\title{
ACUTE CALCIFIC TENDINITIS OF PERONEUS LONGUS
}

\author{
DAVID COX, F. W. N. PATERSON
}

We present a case of acute painful calcific tendinitis in the peroneus longus tendon which responded dramatically to a single steroid injection. Calcific tendinitis is most commonly seen in the supraspinatus tendon; less common sites include the wrist, elbow, deltoid insertion, gluteus maximus, knee, neck and forefoot (Hayes et al 1987). To our knowledge acute calcific tendinitis in peroneus longus has not previously been reported. subtalar joints although forced inversion exacerbated the pain (Rhodes and Stelling 1986). A lateral radiograph (Fig. 1) showed homogeneous calcification extending from the calcaneum to the under surface of the cuboid in the line of the peroneus longus tendon.

The area of maximum tenderness was injected with steroid (Depomedrone $40 \mathrm{mg}$ mixed with local anaesthesia) and the patient was instructed to rest the ankle.

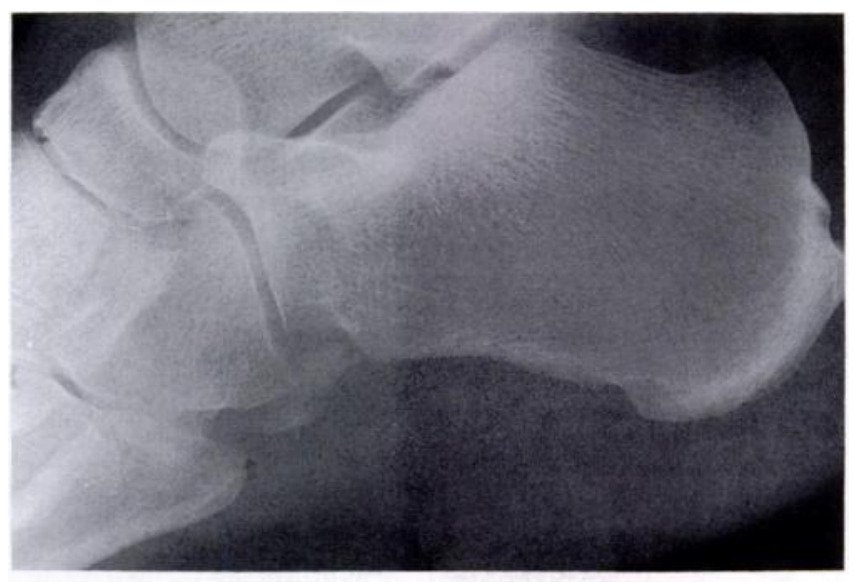

Fig. 1

Case report. A 50-year-old woman presented with a twoweek history of increasing pain on the outer aspect of her right ankle. There had been no history of trauma to the ankle or previous pain. She was a keen ballroom dancer and the pain in her ankle was restricting this.

Examination revealed localised tenderness with associated warmth below and anterior to the lateral malleolus, extending to the under surface of the foot. There was a full range of movement at the ankle and

D. Cox, FRCS, Orthopaedic Registrar

St Bartholomew's Hospital, West Smithfield, London EC1A 7BE, England.

F. W. N. Paterson, FRCS, Consultant Orthopaedic Surgeon

West Middlesex University Hospital, Isleworth, London TW7 6AF, England.

Correspondence to Mr D. Cox.

(C) 1991 British Editorial Society of Bone and Joint Surgery 0301-620X/91/2R03 \$2.00

J Bone Joint Surg [ Br] 1991; 73-B:342.
Immediate relief of symptoms was obtained. At review three weeks later the patient was asymptomatic. There was no tenderness and a further radiograph showed that the area of calcification had decreased in size.

Discussion. The pathogenesis of calcific tendinitis is not completely understood although calcific debris has been shown to provoke pain and inflammation in previously asymptomatic sites (Uhthoff, Sarkar and Maynard 1976). In our case, early presentation and prompt steroid injection into the inflamed area gave dramatic relief.

No benefits in any form have been received or will be received from a commercial party related directly or indirectly to the subject of this article.

\section{REFERENCES}

Hayes CW, Rosenthal DI, Plata MJ, Hudson TM. Calcific tendinitis in unusual sites associated with cortical bone erosion. AJR 1987; 149:967-70.

Rhodes RA, Stelling CB. Calcific tendinitis of the flexors of the forefoot. Ann Emerg Med 1986; 15:751-3.

Uhthoff HK, Sarkar K, Maynard JA. Calcifying tendinitis: a new concept of its pathogenesis. Clin Orthop 1976; 118:164-8. 